\title{
Gestão educacional e inclusão na produção científica brasileira
}

\author{
Scientific production on educational management and inclusion \\ Producción científica sobre gestión educativa e la inclusión
}

Recebido: 06/07/2021 | Revisado: 13/07/2021 | Aceito: 16/07/2021 | Publicado: 25/07/2021

\author{
Daniele Vieira Araújo Anunciação \\ ORCID: https://orcid.org/0000-0001-9052-864X \\ Universidade Federal do Amazonas, Brasil \\ E-mail: dani_varaujo@hotmail.com.br \\ Wania Ribeiro Fernandes \\ ORCID: https://orcid.org/0000-0001-5040-6293 \\ Universidade Federal do Amazonas, Brasil \\ E-mail: waniafer@gmail.com
}

\begin{abstract}
Resumo
A pesquisa consistiu em levantamento de dissertações e teses coletadas no banco de teses da Coordenação de Aperfeiçoamento de Pessoal de Nível Superior (Capes), em artigos de periódicos e anais da Associação Nacional de Pós-Graduação e Pesquisa em Educação (Anped), visando identificar o estado da arte da produção científica sobre gestão educacional na perspectiva da inclusão na última década. Este trabalho é um recorte da pesquisa, de cunho bibliográfica. Foi identificado um total de 84 documentos, sendo que 30 destes se dedicaram a explorar facetas da educação especial e possíveis desdobramentos na gestão escolar. Tal constatação indica ser esta uma vertente ainda incipiente de pesquisas de estudiosos do campo da gestão educacional, apesar da centralidade que a temática da avaliação vem conquistando nas diretrizes políticas da área. Após a leitura dos resumos, os resultados foram sistematizados em quadros-síntese e em gráficos. Para análise e discussão os trabalhos foram categorizados da seguinte maneira: a) Dissertações, Teses e Periódicos sobre Gestão para Inclusão por Região; b) Dissertações, Teses e Periódicos sobre Gestão para Inclusão por Instituições; c) Produções sobre Gestão para Inclusão por ano. Diante da necessidade de se refletir sobre o papel do gestor na escola inclusiva, a produção científica apresentada mostra a relevância da pesquisa na Região Norte, pois só encontramos um trabalho sobre a gestão escolar para a educação inclusiva no ano de 2016, nos mostrando a importância da reflexão sobre a temática. A produção traz aspectos relevantes que envolvem a busca de um sistema educacional inclusivo, no qual urge a necessidade de se repensar a função do gestor educacional, assim como a articulação de ações inclusivas com a comunidade escolar.
\end{abstract}

Palavras-chave: Gestão educacional; Ensino; Inclusão; Produção científica.

\begin{abstract}
The research consisted of survey of dissertations and theses collected in the thesis database of the Coordination of Improvement of Higher Education Personnel (Capes), in articles of journals and annals of the National Association of Graduate and Research in Education (Anped), aiming to identify the state of the art of scientific production on educational management from the perspective of inclusion in the last decade. This work is a clipping of the research, of bibliographical nature. A total of 84 documents were identified, 30 of which were devoted to exploring facets of special education and possible developments in school management. This finding indicates that this is still an incipient aspect of research by scholars in the field of educational management, despite the centrality that the evaluation theme has been conquering in the political guidelines of the area. After reading the abstracts, the results were systematized in summary tables and graphs. For analysis and discussion, the works were categorized as follows: a) Dissertations, Theses and Periodicals on Management for Inclusion by Region; b) Dissertations, Theses and Journals on Management for Inclusion by Institutions; c) Productions on Management for Inclusion per year. Given the need to reflect on the role of the manager in inclusive school, the scientific production presented shows the relevance of research in the Northern Region, as we only found work on school management for inclusive education in 2016, showing us the importance reflection on the theme. The production brings relevant aspects that involve the search for an inclusive educational system, which urges the need to rethink the role of the educational manager, as well as the articulation of inclusive actions with the school community.
\end{abstract}

Keywords: Educational management; Teaching; Inclusion; Scientific production.

\section{Resumen}

La investigación consistió en una encuesta de disertaciones y tesis recopiladas en la base de datos de tesis de la Coordinación de Mejoramiento del Personal de Educación Superior (Capes), en artículos de revistas y anales de la Asociación Nacional de Graduados e Investigación en Educación (Anped), con el objetivo de identificar El estado del arte de la producción científica sobre gestión educativa desde la perspectiva de la inclusión en la última década. Este 
trabajo es un recorte de la investigación, de naturaleza bibliográfica. Se identificaron un total de 84 documentos, 30 de los cuales se dedicaron a explorar las facetas de la educación especial y los posibles desarrollos en la gestión escolar. Este hallazgo indica que este sigue siendo un aspecto incipiente de la investigación realizada por académicos en el campo de la gestión educativa, a pesar de la centralidad que el tema de la evaluación ha estado conquistando en las pautas políticas del área. Después de leer los resúmenes, los resultados se sistematizaron en tablas de resumen y gráficos. Para su análisis y discusión, los trabajos se clasificaron de la siguiente manera: a) Disertaciones, Tesis y Publicaciones periódicas sobre Gestión para la inclusión por región; b) Disertaciones, Tesis y Revistas sobre Gestión para Inclusión por Instituciones; c) Producciones sobre gestión para la inclusión por año. Dada la necesidad de reflexionar sobre el papel del gerente en la escuela inclusiva, la producción científica presentada muestra la relevancia de la investigación en la Región Norte, ya que solo encontramos trabajo en la gestión escolar para la educación inclusiva en 2016, lo que nos muestra la importancia Reflexión sobre el tema. La producción trae aspectos relevantes que implican la búsqueda de un sistema educativo inclusivo, lo que urge la necesidad de repensar el papel del gerente educativo, así como la articulación de acciones inclusivas con la comunidad escolar.

Palabras clave: Gestión educativa; Enseñanza; Inclusión; Producción científica.

\section{Introdução}

Atualmente evidencia-se no sistema educacional brasileiro o movimento que defende o acesso e democratização do ensino, com vistas a assegurar uma educação que atenda a todos, sendo, desse modo, inclusiva, equitativa e de qualidade. A defesa pela educação inclusiva, entendida como uma ação social, política, cultural e pedagógica visa garantir que todos os alunos tenham direito a aprender juntos sem nenhum tipo de discriminação (BRASIL, 2008).

Segundo o Instituto Brasileiro de Geografia e Estatísticas (IBGE), em 2010, 23,9\% da população brasileira apresentava algum tipo de deficiência sensorial, motora ou intelectual. O processo de inclusão dessas pessoas na escola tem sido defendida com base no pressuposto basilar da sociedade democrática, a Declaração Universal dos Direitos Humanos (1948), que em seu artigo $1^{\circ}$ defende a liberdade e igualdade como direito de todos ao afirmar que todas as pessoas nascem livres e iguais em dignidade e direitos. Porém, a implementação desse processo inclusivo educacional tem sido um dos grandes desafios para a gestão educacional cuja ação é determinante para a democratização do acesso e inclusão de todos no sistema educacional brasileiro.

A gestão educacional nacional, desde a Lei de Diretrizes e Bases $\mathrm{N}^{\circ}$ 9394/96, assume um caráter democrático privilegiando a participação dos profissionais da educação e de toda comunidade escolar no planejamento e desenvolvimento do Projeto pedagógico educacional a fim de que este reflita e atenda as especificidades de cada região e/ou comunidade escolar. Entretanto, são os princípios democráticos que norteiam o trabalho do gestor o elemento a influenciar não só os planos e ações de inclusão que a escola irá desenvolver, mas também a forma como tais ações se materializarão na rede regular de ensino.

A gestão educacional é baseada na organização dos sistemas de ensino nas três esferas de governo federal, estadual e municipal onde cada instância tem um papel no contexto educacional do país. Trata das incumbências desses sistemas e a partir das várias formas de articulação entre as instâncias determinam-se "normas", executam e deliberam sobre a oferta da educação no setor público e privado. Essa gestão educacional propicia uma observação macro sobre a escola e permite inferências sobre questões educacionais nacionais mediante visão de conjunto. Assim, cabe a gestão educacional fomentar, defender e garantir uma gestão democrática na perspectiva inclusiva que encurta distâncias entre a sociedade e a escola para que a gestão escolar possa se concretizar de forma eficiente na rede regular de ensino.

Nessa compreensão, segundo Paro (2018), o gestor escolar deve vir da própria comunidade, como resultado de um processo político horizontal, de quem conhece, vivencia e compreende os interesses e necessidades da sua comunidade local, e não como resultado de processo político verticalizado, por indicação, visto que este traem si uma visão de gestão especificamente administrativa, cujo foco se alinha mais diretamente com os interesses do Estado. Cabe a gestão escolar elaborar e executar sua proposta pedagógica, administrar seus recursos humanos, materiais e financeiros; cuidar do ensino- 
aprendizado do seu alunado, proporcionando meios para a seu desenvolvimento, além de proporcionar um processo integrador entre comunidade, família e escola. Considerando, portanto, que os estabelecimentos de ensino, são organismos vivos, dinâmicos, constituídos por uma rede de relações cujo grau de participação, engajamento ou centralização, que irá preponderar na comunidade escolar, tem relação direta com a prática de gestão instituída, podemos entender que o que caracteriza as diversas formas de gerir uma instituição e seus interesses é o viés político e de poder que marca a gestão.

Autores como Lück (2103), Przylepa (2019) e Brasil (2018), defendem que o caminho que a gestão deveria percorrer, na perspectiva de uma educação democrática e inclusiva, é o da descentralização que possibilitaria a autonomia para o gestor desenvolver trabalho conjunto, ou seja, envolvendo toda a comunidade escolar sem distinção. A relevância da participação da direção, da coordenação pedagógica, de professores(as), da equipe administrativa, de serviços gerais, da segurança, de responsáveis pela alimentação (merendeiras), de zeladores, pais, mães, representantes da comunidade, nessa perspectiva, deveria ser a mesma, visto que, pensar a realidade local e as melhores estratégias educacionais para a comunidade precisaria ser trabalho coletivo com a contribuição de todos sem exceção. E a gestão, ao abrir as portas da escola para inserir os pais em projetos, em cursos, na vida educacional de seus filhos, torna-os agentes e responsáveis sociais no processo de tomada de decisões da vida escolar, levando em consideração as demandas sociais daquela comunidade singular.

A gestão democrática na perspectiva da educação inclusiva assume que as diferenças são normais e que, portanto, cabe a escola se adaptar às necessidades da criança e ao assumir essa posição pedagógica, centrada no estudante, cria um envolvimento ativo e reativo de toda comunidade escolar para o desenvolvimento de cooperação efetiva e de trabalho em grupo no sentido de atender as necessidades dos estudantes, beneficiando à sociedade como um todo.

Tal pressuposto é defendido por autoras como Matos (2013) e Glat (2017) que identificam que na atualidade os princípios, políticos e práticas educativas, caminham para a formação dessa escola para todos, que atenda às necessidades e especificidades dos alunos, investindo em formação de recursos humanos e práticas educativas que visam atender os que durante muitos anos estiveram à margem do processo educacional

O mapeamento da produção brasileira sobre a interface gestão e inclusão na última década nos permite refletir sobre desafios ainda presentes e possíveis avanços instituídos na dinâmica das práticas desenvolvidas nas escolas.

\section{Metodologia}

O percurso metodológico adotado para essa pesquisa foi de caráter empírico, de natureza qualitativa, considerando que esse tipo de abordagem se preocupa com valores, crenças, significados construídos nas inter-relações humanas (Minayo, 2010). Para a obtenção de dados a pesquisa qualitativa tem como fonte as situações estudadas, enfatizando as formas de manifestação, os procedimentos e as interações cotidianas do fato investigado, bem como retratam a perspectiva dos participantes. Responde sempre a questões muito particulares e se preocupa, nas ciências sociais, com um nível de realidade que não pode ser quantificado. Ou seja, ela trabalha com o universo de significados, motivos, aspirações, crenças, valores e atitudes, o que corresponde a um espaço mais profundo das relações, dos processos e dos fenômenos que não podem ser reduzidos à operacionalização de variáveis (Lakatos, 2010). Todavia é importante destacar que não existe um "continuum" entre "qualitativo-quantitativo", em que o primeiro termo seria o lugar da "intuição", da "exploração" e do "subjetivismo"; e o segundo representaria o espaço do científico, porque traduzido "objetivamente" e em "dados matemáticos". A diferença entre qualitativo - quantitativo é de natureza. Enquanto cientistas sociais que trabalham com estatística apreendem dos fenômenos apenas a região "visível, ecológica, morfológica e concreta", a abordagem qualitativa aprofunda-se no mundo dos significados das ações e relações humanas, um lado não perceptível e não captável em equações, médias e estatísticas (Minayo, 2010, p.22).

O objetivo foi realizar o estado da arte das produções científicas brasileiras sobre gestão educacional na perspectiva da inclusão, compreendendo o período de 2008 a 2017. Para tal foram utilizadas como fonte de dados a Biblioteca Digital 
Brasileira de Teses e Dissertações (BDTD); o Banco de Teses e Dissertações da Capes; os Anais das reuniões anuais da Associação Nacional de Graduação e Pesquisa em Educação (Anped) do Grupo de Trabalho (GT) Educação Especial e da Scientific Eletronic Library Online (SciELO) utilizando-se como unitermos "gestão"; "inclusão" e "educação".

\section{Resultados e Discussão}

Foram pesquisados trabalhos e artigos científicos cujo título apresentasse o termo gestão, sendo selecionados 15 artigos duas teses e 13 dissertações, totalizando 30 trabalhos.

Para análise os trabalhos foram separados por categorias considerando região, Instituição e ano de publicação, conforme sistematizado a seguir. O Gráfico 1 apresenta a distribuição dos trabalhos por região.

Gráfico 1- Produção Científica por Região entre 2008 a 2017.

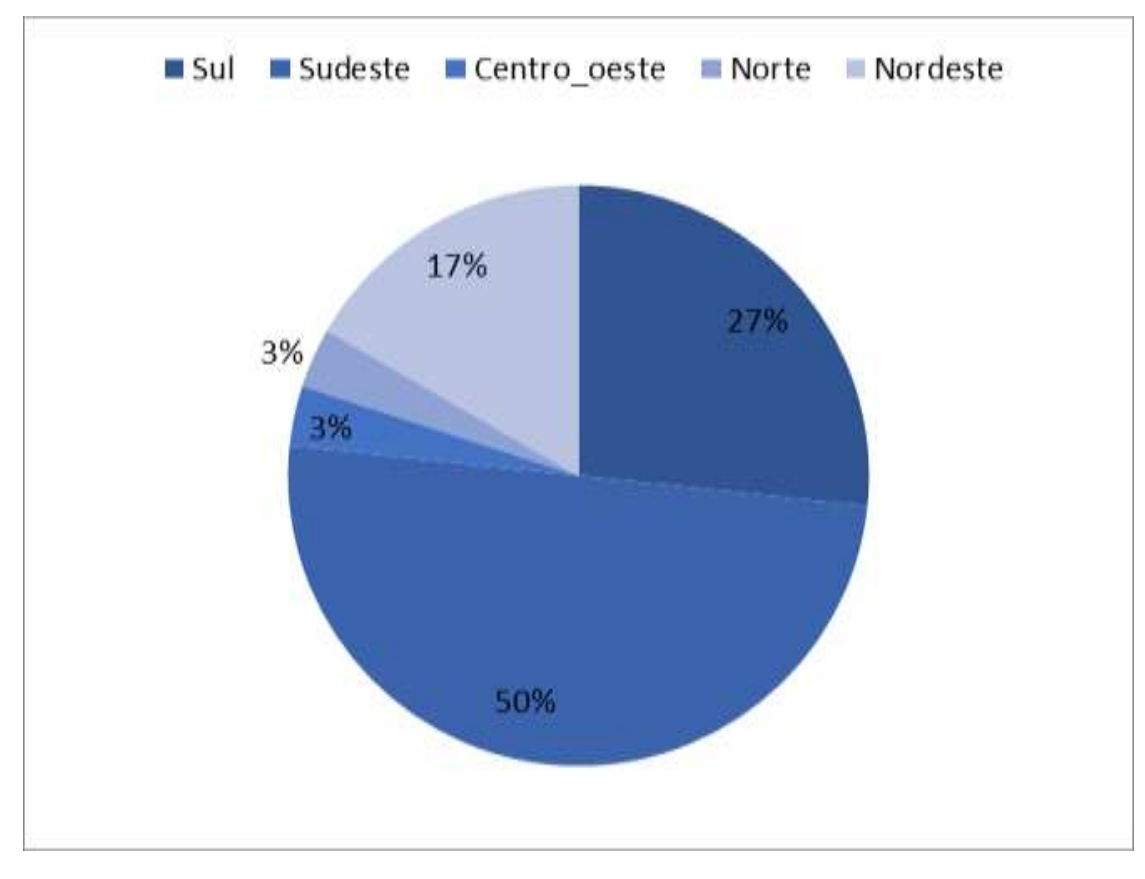

Fonte: Autores.

Podemos observar no gráfico que 50\% da produção nacional sobre a temática da gestão na perspectiva da inclusão no período de 2008 a 2017 se concentrou na Região Sudeste, o que totaliza 15 trabalhos. Na Região Sul foram produzidos oito trabalhos, representando $27 \%$ do total. Na Região Nordeste foram publicados cinco trabalhos totalizando $17 \%$ da produção nacional e nas regiões Centro-Oeste e Norte foi identificado um único trabalho em cada, o que representa 3\% das publicações. Tais dados indicam a concentração de produção na região Sudeste e a importância de trazer essa discussão para debate nas regiões norte e centro-oeste.

Quando analisamos a produção científica considerando a Instituição de origem observamos que 19 Instituições de Ensino Superior (IES) desenvolveram trabalhos com a temática, conforme apresentado no Gráfico 2 abaixo. 
Gráfico 2 - Distribuição de Dissertações e Teses por Instituições.

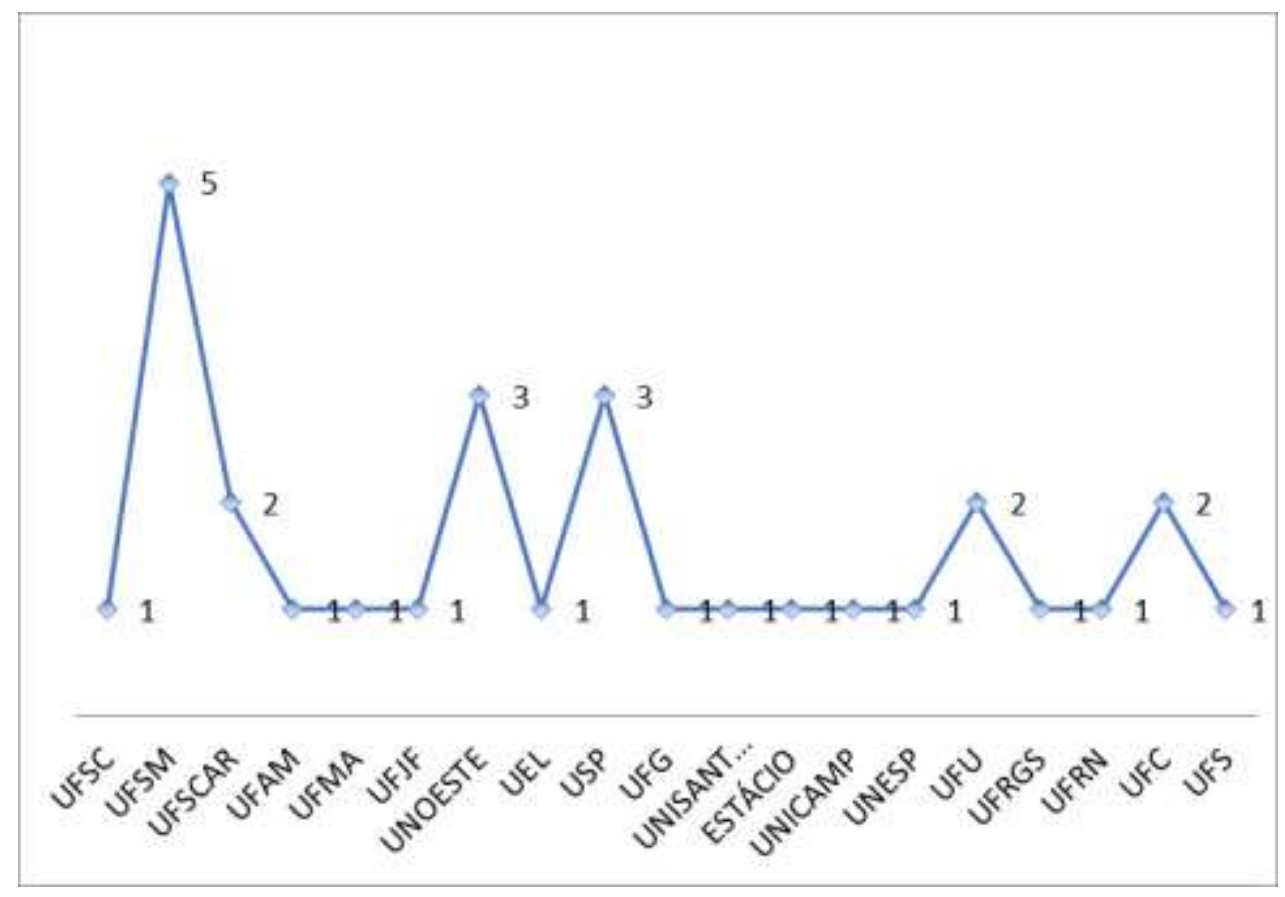

Fonte: Autores.

O gráfico nos possibilita visualizar que das 19 IES que tiveram teses e/ou dissertações sobre o tema gestão escolar e inclusão, nove estão localizadas na Região Sudeste do Brasil, sendo dois trabalhos da Universidade Federal de São Carlos (UFSCar), três da Universidade do Oeste Paulista (Unoeste), três da Universidade de São Paulo (USP), dois da Universidade Estadual de São Paulo (Unesp), um trabalho da Universidade Federal de Uberlândia (UFU); um da Universidade Católica de Santos (Unisantos), um da Universidade Estácio de Sá, um da Universidade Estadual de Campinas (Unicamp) e um trabalho da Universidade Federal de Juiz de Fora (UFJF). Em seguida, com a participação de quatro IES, temos a Região Nordeste onde houve defesa de um trabalho sobre a temática na Universidade Federal de Sergipe (UFS), na Universidade Federal do Maranhão (UFMA), na Universidade Federal do Rio Grande do Norte (UFRN) e de dois trabalhos na Universidade Federal do Ceará (UFC); e a Região Sul onde também em quatro instituições houve defesa sendo cinco delas na Universidade Federal de Santa Maria (UFSM); uma na Universidade Federal de Santa Catarina (UFSC), uma na Universidade Estadual de Londrina (UEL) e uma na Universidade Federal do Rio Grande do Sul (UFRGS). Na região Centro-Oeste identificamos apenas a Universidade Federal de Goiás (UFG) onde houve uma defesa, o mesmo ocorrendo na Região Norte onde apenas na Universidade Federal do Amazonas (UFAM) houve a defesa de um trabalho sobre o tema. Tal distribuição mostra ainda o quanto o tema é pouco abordado nas teses e dissertações na região Norte e Centro-Oeste e a necessidade de darmos visibilidade a esta questão e incentivarmos as pesquisas nesta interface gestão escolar/educacional e inclusão.

Quando fazemos nossa análise das produções científicas por ano de publicação observamos um decréscimo importante das mesmas entre 2008 e 2017, conforme o Gráfico 3 a seguir. 
Gráfico 3 - Distribuição de Publicações Científicas por Ano.

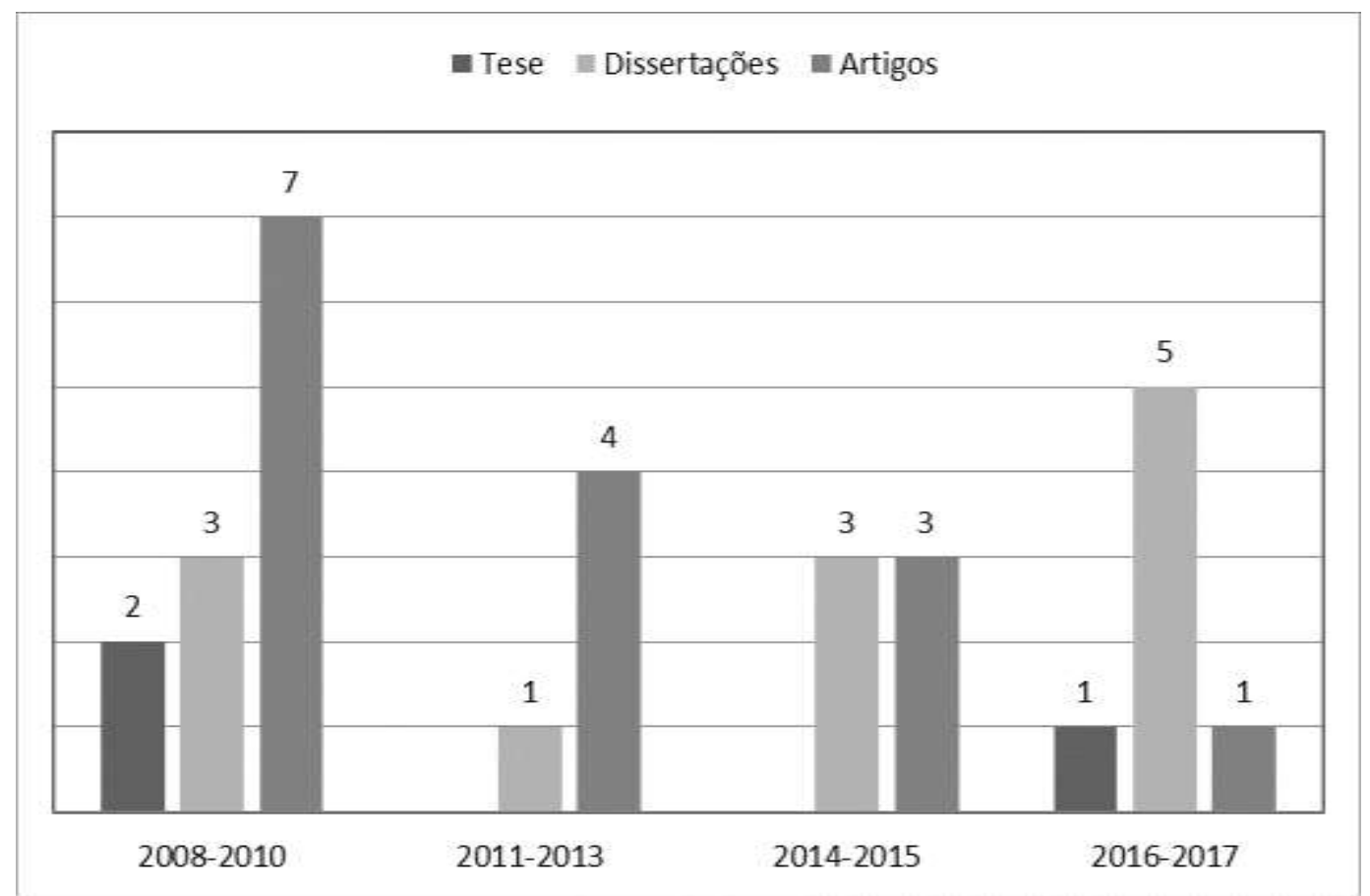

Fonte: Autores.

É possível identificar que o biênio 2008-2010 foi o de maior produção de artigos científicos, com sete produções, e com duas defesas de tese e três dissertações. O período de 2011 a 2013 traz um declínio na publicação de artigos, de sete para quatro, na defesa de dissertações, de três para uma, e ausência de tese sobre a temática. Entre os anos de 2014 e 2015 não há defesa de tese e são defendidas três dissertações e a produção de artigo científico mantém o declínio quando comparado ao período anterior, de quatro para três publicações. Entre os anos de 2016 e 2017 apenas uma tese e um artigo são produzidos, mas sobe para cinco o número de dissertações defendidas. Tais dados refletem a necessidade de se manter o incentivo às pesquisas e reflexões sobre a temática da gestão para a inclusão escolar a fim de que haja possibilidade de difusão de novas práticas ou de experiências exitosas que venham a contribuir para mudanças propositivas qualitativamente significativas no cenário educacional.

\subsection{Noção de Inclusão Limitada ao Aspecto Estrutural}

Ao realizarmos a análise textual dos trabalhos publicados no período de 2008 a 2017, foi possível identificar algumas questões que permeiam todos os trabalhos e que buscamos trazer para reflexão. Todavia deixamos claro que essa análise não visa esgotar todas as questões possíveis de serem discutidas, mas antes refletir sobre questões que consideramos basilares na interface gestão e inclusão.

\subsection{Noção de Inclusão Limitada ao Aspecto Estrutural}

A pesquisa desenvolvida por Boaventura (2008) destaca que nos discursos dos gestores das escolas analisadas a educação inclusiva é pensada de forma limitante na medida em que são consideradas mais especificamente as questões estruturais, como aspectos físicos, arquitetônicos das escolas. O conceito de acesso fica restrito ao âmbito de adaptações arquitetônicas para o ingresso dos alunos público alvo da educação especial. Tal entendimento é corroborado no trabalho de Valim (2013) cujos gestores escolares das escolas pesquisadas desenvolvem algumas ações tidas como inclusivas não sendo possível afirmar que em todos os momentos o gestor escolar consegue promover a inclusão dos alunos pois os membros da 
comunidade escolar têm concepções diferentes sobre inclusão escolar/social e esse trabalho não é possível de ser realizado sozinho e Santos (2016) que aponta um processo de aquisição de uma concepção inclusiva, mas ainda com ranços da integração permeando o conjunto ideológico dos gestores escolares consubstanciam os seus valores, noções, saberes e fazeres acerca da inclusão dos alunos no PAEE e em outras ainda restritas à socialização do aluno com deficiências ou sem, imprimindo a escola um espaço de convivência plural que contribui para a formação de cidadãos mais tolerantes com respeito ao que lhe diferente e diverso. Também o estudo de Caiado (2008), verificou a ausência de financiamento para a formação dos profissionais de educação; averiguou tensões AEE privado e público, como também confrontos com o discurso das concepç̃es conceituais do Programa e os gestores e inconsistências em algumas diretrizes.

\subsection{Gestão para Educação Inclusiva não contempladas no Projeto Político Pedagógico (PPP)}

Silva Santos (2008), em seu estudo relata que o entendimento sobre os princípios que norteiam a proposta de educação inclusiva na unidade escolar ainda não está bem definido para os gestores, apesar de prevalecer o entendimento de gestão compartilhada, os gestores não mostraram a necessidade dessa gestão para uma escola inclusiva. Contudo, concluiu que a gestão para educação inclusiva são pontuais, isoladas e não estão fundamentadas, organizadas ou planejadas nas diretrizes gerais da escola e Tezani (2008) verificou a inexistência do PPP construído coletivamente, dificuldade ao desenvolvimento de ações das coordenadas e adaptadas às realidades existentes, problemas de relacionamento interpessoal, um enorme fosso entre a proposta política, o discurso político pregado e a prática pedagógica cotidiana realizada. A gestão, é sim, uma das responsáveis pela construção da escola inclusiva, mas sua prática está direcionada às questões administrativas em detrimentos as pedagógicas

\subsection{Avanços na Execução da Política}

Quintairos (2015) em sua pesquisa mostrou os avanços na execução dessa política, sobretudo pela atuação determinante do Ministério Público, notadamente um órgão externo à gestão. Contudo resta ainda um longo caminho a percorrer na implementação e gestão da política de educação especial inclusiva no contexto analisado. Reconhe assim que as Diretorias de Ensino e as Unidades Escolares - em meio a suas características próprias e peculiares - dispõem de uma considerável autonomia na maneira de encampar uma determinada política educacional, não se configurando em mera executora de deliberações, mas constituindo uma instancia de reação e reinterpretação das políticas e ações de gestão na qual se vê envolvida. Apesar das dificuldades e entraves é possível reconhecer avanços na execução de uma política de educação inclusiva, ainda que sob a pressão e atuação determinante de instancias exterior à gestão, em especial as normativas do MP que zela pela garantia dos direitos inalienáveis na Constituição Federal vigente alinhada à observação da declaração universal dos Direitos Humanos. Em termos de uma política pública de atendimento às pessoas com deficiência podemos reconhecer conquistas importantes e inéditas no âmbito da diretoria de ensino - região Santos. Contudo há ainda um longo e árduo caminho a percorrer.

\subsection{Formação de Gestores}

Noya (2016) na sua pesquisa mostra o apelo a novos modos de ser gestor, implicados, também, na captura da Educação Especial enquanto área de saber e da diferença nos processos de formação de gestores para a inclusão. Essa discursividade está alojada na necessidade de envolver a todos na gestão da inclusão, por meio de princípios da gestão democrática. O deslocamento de ênfase dos discursos da administração para a gestão educacional é tomado nesta pesquisa como estratégia de condução de conduta. A atual ênfase do discurso de descentralização da gestão para a educação Inclusiva intensifica a centralidade no gestor, que sob o discurso democrático, a participação e a liderança, precisam produzir modos de 
estar na escola contemporânea. Freitas (2014) relata que a formação foi desenvolvida por meio de estratégias de multiplicação e de descentralização da formação do governo federal para o municipal onde por meio da adesão do município-polo este passa a ser o responsável pela formação dos demais municípios de sua abrangência. A formação é desenvolvida através de seminários anuais, os quais possuem uma carga horária que variam de 20 a 40 horas, evidenciando-se uma ausência de tempo hábil para sanar dúvidas e gerar discussões mais aprofundadas dos temas, tendo um caráter reprodutivista, o que é uma contradição, uma vez que se forma para a inclusão e não se leva em conta a diversidade e diferenças de realidades dos municípios envolvidos. Por fim, esclarece-se que por meio da leitura e análise dos documentos, pode-se perceber que os conteúdos teóricos propostos são enriquecedores por sua natureza, mas essa significante colaboração pode ser perdida devido às limitações práticas de sua concretização.

\subsection{Gestão Compartilhada}

Silveira (2009), nesse estudo o acompanhamento na escola permitiu avanços em alguns pontos: a interiorização da cultura de cooperação entre a gestão da escola e os professores, especialmente aqueles que foram acompanhados por membros da pesquisa, a criação da cultura do acolhimento de todos os alunos por parte da gestão, a reorganização das ações do planejamento, reforço das ações no âmbito da gestão participativa, investimento na diversificação dos equipamentos pedagógicos e na infra-estrutura da escola, a sistematização das ações da direção através da partilha e reciprocidade na tomada de decisões, e investimento na formação de professores e membros da equipe gestora e Rocha (2012), relata em sua pesquisa colaborativa, que o acompanhamento permitiu avanços em alguns pontos: a de interiorização da cultura e cooperação entre a gestão da escola e professores, principalmente aqueles acompanhados por membros da pesquisa, a criação da cultura de acolhimento a todos os alunos por parte da gestão, a reorganização das ações e planejamento, reforço das ações no âmbito da gestão participativa, investimento na diversificação dos equipamentos pedagógicos e na infra-estrutura da escola, a sistematização das ações da direção através da partilha e reciprocidade na tomada de decisões e investimento na formação de professores e membros da equipe gestora.

\subsection{Planejamento Pedagógico no AEE}

Varella (2016), revela dificuldade na organização em função de o planejamento pedagógico ser realizado de forma assistemática. Os dados censitários escolares também se mostraram imprecisos e discordantes. Evidenciou-se distanciamento entre o que preceitua a política e as práticas na gestão. A educação especial não se organizava como uma modalidade transversal a todas as etapas da educação.

\subsection{Relevância da Pesquisa}

Fagliari (2013), evidenciou na pesquisa a necessidade de continuar a empreender estudos sobre a política federal não abordadas ou pouco exploradas, tais como: a materialização de práticas colaborativas entre o professor de educação especial e da classe comum, a investigação sobre o processo de inclusão escolar de alunos surdocegos e com múltiplas deficiências, o atendimento educacional especializado na educação infantil e práticas avaliativas concernente ao público alvo da educação especial e Mari da Rocha (2016) sinaliza a pouca representatividade da modalidade da educação especial nas secretarias municipais de educação, além do desconhecimento dos gestores sobre os fundamentos que normatizam a política de educação inclusiva. A educação municipal tem sua gestão influenciada por diretrizes nacionais e//ou estaduais que apresentam, muitas vezes, contraditoriedade de princípios e ações. 


\section{Conclusão}

Diante da necessidade de se refletir sobre o papel do gestor na escola inclusiva, a produção científica apresentada mostra a relevância da pesquisa na Região Norte, pois só encontramos um trabalho sobre a gestão escolar para a educação inclusiva no ano de 2016, nos mostrando a importância da reflexão sobre a temática.

A produção traz aspectos relevantes que envolvem a busca de um sistema educacional inclusivo, no qual urge a necessidade de se repensar a função do gestor educacional, assim como a articulação de ações com a equipe pedagógica e comunidade escolar para a construção da escola inclusiva, pois o envolvimento de todos é parte integrante desse processo.

Neste sentido a escola inclusiva precisa estar alicerçada na gestão democrática, participativa e autônoma, fomentar formação de professores, contextualizarem no Projeto Político Pedagógico (PPP) a realidade na qual está inserida para promoção de estratégias que atendam às necessidades e especificidades dos alunos.

Portanto, que a gestão assuma realmente seu papel e sua função democrática, para um Brasil efetivamente justo, igual e plural em toda a instância da sociedade e assim, desejamos que esta pesquisa possa ser útil e que suscite novos questionamentos, outras produções e desenvolvimento de ações para a continuidade dos estudos e sucesso acadêmico dos alunos

\section{Referências}

Boaventura, R. S. (2008). A gestão escolar na perspectiva da inclusão. 2008.122 f. Dissertação (Mestrado em Educação). Universidade do Oeste Paulista, Presidente Prudente, SP.

Brasil, R. S. (2018). Gestão democrática na escola pública e o programa mais educação. Appris.

Brasil (2008). Política Nacional de Educação Especial na Perspectiva da Educação Inclusiva. Documento elaborado pelo Grupo de Trabalho nomeado pela Portaria n ${ }^{\circ}$ 555/2007, prorrogada pela Portaria n 948/2007, entregue ao Ministro da Educação em 07 de janeiro de 2008.

Brasil. (1996). Lei de Diretrizes e Bases da Educação nº 9.394/96, de 20 de dezembro de 1996.

Glat, Rosana, et al (2007) Educação Inclusiva: cultura e cotidiano escolar. Rio de Janeiro: 7 Letras.

Henriques, R e et al. (2020). Gestão na educação em larga escala: jovem do futuro de projeto piloto em escolas para uma política da rede pública. Instituto Unibanco, São Paulo, SP.

Lakatos, E. M., \& Marconi, M (2010). Fundamentos de metodologia científica: técnicas de pesquisa. (7ªd.): Atlas,2010.

Lima,A. B. \& Silva, M.B.(2018). Gestão escolar democrática: teorias e práticas. Universidade Federal de Uberlândia: Navegando.

Lima, E. C. V. (2016). Gestão escolar e política educacional de inclusão na rede de ensino municipal de Manaus: um reflexo à luz da teoria crítica. 2016. f142. Dissertação (Mestrado em Educação). Universidade Federal do Amazonas, Manaus, AM.

Lück, H. (2006). Concepções e processos democráticos da Gestão Educacional. (2ª ed.): Vozes.

Lück, H. (2006). Gestão Educacional: uma questão paradigmática. (1ªed.): Vozes.

Lück, H. (2013). Concepções e processos democráticos de gestão educacional. Vozes.

Matos, M. A. S. (2013). Cidadania, Diversidade e Educação inclusiva: um diálogo entre a teoria e a prática na escola pública. Manaus, AM: EDUA.

Mello, M. N. (2014). O papel da gestão na implementação de políticas públicas de educação especial. 2014.f.112. Dissertação (Mestrado em Educação). Universidade Estácio de Sá, Rio De Janeiro, RJ.

Minayo, M. C. et al. (2010). Pesquisa Social. Teoria, método e criatividade. (29a ed): Vozes.

Michels, M. H. (2006). Gestão, formação docente e inclusão: eixos da reforma educacional brasileira que atribuem contornos à organização escolar. Revista Brasileira de Educação. [s.33].p.406-423.

Paro, V. H. (2018). Gestão escolar, democracia e qualidade do ensino. Intermedio.

Przylepa,M (2019). Políticas públicas e gestão educacional: retrocessos, permanências e avanços no século XXI. (1 ${ }^{\mathrm{a} e d)}$ : Paco, 2019.

Rosa, I. G. (2009). A gestão escolar democrática: o caso da rede municipal de Mesquita/RJ. 2009. f.138.Dissertação (Mestrado em Educação). Universidade Federal do rio de Janeiro, Rio de Janeiro, RJ.

Santos, M. P dos. (2002). Educação inclusiva: redefinindo a educação especial. Revista Ponto de Vista., [s. 3]. p. $103-118$. 
Research, Society and Development, v. 10, n. 9, e25610917969, 2021

(CC BY 4.0) | ISSN 2525-3409 | DOI: http://dx.doi.org/10.33448/rsd-v10i9.17969

Santos, R. R. S. (2011). Gestão escolar para uma escola inclusiva: conquistas e desafios. 2011.f. 91. Dissertação (Mestrado em Educação). Universidade do Oeste Paulista, Presidente Prudente, SP.

Santos, J. T. P. A. (2016) A gestão escolar na construção de uma escola inclusiva: fundamentos e prática na rede de ensino fundamental de São Luís/MA. 2016. f. 106.Dissertação(Mestrado em Educação). Universidade Federal de São Luís, MA.

Souza, A. R. (2006). Perfil da Gestão Escolar do Brasil. 2006. f..302. Tese (Doutorado em Educação). Pontifícia Universidade Católica de São Paulo, São Paulo.

Valim, R. A A. (2013). O papel do gestor escolar para uma escola inclusiva do Ensino Fundamental I. 2013.f.88. Dissertação (Mestrado em Educação). Universidade de São Paulo. São Paulo, SP.

Veiga, I. P. A. (2008). Projeto pedagógico da escola: uma construção coletiva. (24ª ed.):Papirus.

Veiga, I. P .A. (2009). Projeto Político-Pedagógico e gestão democrática Novos marcos para a educação de qualidade. Revista Retratos da Escola, Brasília, [s.4], p. 163- 171 . 